\title{
Preservation of the Myofascial Cuff During Posterior Fossa Surgery to Reduce the Rate of Pseudomeningocele Formation and Cerebrospinal Fluid Leak: A Technical Note
}

\author{
Daniel R. Felbaum ${ }^{1}$, Kyle Mueller ${ }^{2}$, Amjad Anaizi ${ }^{2}$, Robert B. Mason ${ }^{2}$, Walter C. Jean ${ }^{2}$, \\ Jean-Marc Voyadzis ${ }^{1}$ \\ 1. Neurosurgery, Medstar Georgetown University Hospital, Washington DC, USA 2. Neurosurgery, \\ Medstar Georgetown University Hospital
}

$\square$ Corresponding author: Kyle Mueller, kyle.mueller85@gmail.com

Disclosures can be found in Additional Information at the end of the article

\section{Abstract}

Introduction: Suboccipital craniotomy is a workhorse neurosurgical operation for approaching the posterior fossa but carries a high risk of pseudomeningocele and cerebrospinal fluid (CSF) leak. We describe our experience with a simple T-shaped fascial opening that preserves the occipital myofascial cuff as compared to traditional methods to reduce this risk.

Methods: A single institution, retrospective review of prospectively collected database was performed of patients that underwent a suboccipital craniectomy or craniotomy. Patient data was reviewed for craniotomy or craniectomy, dural graft, and/or sealant use as well as CSF complications. A pseudomeningocele was defined as a subcutaneous collection of cerebrospinal fluid palpable clinically and confirmed on imaging. A CSF leak was defined as a CSF-cutaneous fistula manifested by CSF leaking through the wound. All patients underwent regular postoperative visits of two weeks, one month, and three months.

Results: Our retrospective review identified 33 patients matching the inclusion criteria. Overall, our cohort had a $21 \%(7 / 33)$ rate of clinical and radiographic pseudomeningocele formation with 9\% (3/33) requiring surgical revision or a separate procedure. The rate of clinical and radiographic pseudomeningocele formation in the myofascial cuff preservation technique was less than standard techniques (12\% and 31\%, respectively). Revision or further surgical procedures were also reduced in the myofascial cuff preservation technique vs. the standard technique (6\% vs $13 \%$ ).

Received 12/17/2016

Review began 12/21/2016 Review ended 12/23/2016 Published 12/28/2016

\section{(C) Copyright 2016}

Felbaum et al. This is an open access article distributed under the terms of the Creative Commons Attribution License CC-BY 3.0., which permits unrestricted use, distribution, and reproduction in any medium, provided the original author and source are credited.
Conclusions: Preservation of the myofascial cuff during posterior fossa surgery is a simple and adoptable technique that reduces the rate of pseudomeningocele formation and CSF leak as compared with standard techniques.

Categories: Medical Education, Infectious Disease, Neurosurgery

Keywords: posterior fossa, chiari decompression, pseudomeningocele, meningitis, lumbar drain, cerebellum

\section{Introduction}

Suboccipital craniotomy is a workhorse neurosurgical operation for approaching the posterior fossa [1-2]. Because of its gravity-dependent location, posterior fossa approaches carry a higher

How to cite this article

Felbaum D R, Mueller K, Anaizi A, et al. (December 28, 2016) Preservation of the Myofascial Cuff During Posterior Fossa Surgery to Reduce the Rate of Pseudomeningocele Formation and Cerebrospinal Fluid Leak: A Technical Note. Cureus 8(12): e946. DOI 10.7759/cureus.946 
risk of pseudomeningocele and cerebrospinal fluid leak (CSF) [3]. In the reported literature, with various underlying pathologies and radiographic or clinical criteria, the rate of pseudomeningocele rate can be as high as $40 \%$ [4-5].

The technique of suboccipital craniotomy typically involves a midline or hockey stick incision, a wide subperiosteal detachment of the posterior musculature from the occipital bone, and dorsal spinal elements. The potential for dead space, combined with the difficulty in reattachment of the musculoligamentous tissues to the occipital bone, creates a direct conduit for cerebrospinal fluid to reach the skin. This is compounded by the thin and typically friable dura of the posterior fossa [6-7].

We describe our experience during posterior fossa surgery with a simple technique that preserves the occipital myofascial cuff formed from the insertion of the paraspinous musculature of the occipital bone. A T-shaped fascial opening is performed during the initial dissection that allows for watertight reattachment of the paraspinal musculature to the spinal elements and occipital bone, reducing dead space and eliminating a CSF conduit to the skin. Our hypothesis is that this simple technical nuance should reduce the rate of pseudomeningocele formation or cerebrospinal fistula. To the authors' knowledge, there has been no previous study investigating the efficacy of this technique.

\section{Technical Report}

We performed a retrospective review of a prospectively collected database of patients that underwent a suboccipital craniotomy or craniectomy preserving the myofascial cuff compared to the traditional method. Each procedure had a midline incision, suboccipital craniotomy or craniectomy, dural graft, and sealant. This limited the major technical difference between techniques to the preservation of the myofascial cuff. We analyzed each patient's postoperative course for any surgical complications, with particular attention paid to pseudomeningocele formation, CSF leak, and wound dehiscence, or meningitis. A pseudomeningocele was defined as a subcutaneous collection of cerebrospinal fluid palpable clinically and confirmed on imaging. A CSF leak was defined as a CSF-cutaneous fistula manifested by CSF leaking through the wound. All patients underwent postoperative imaging in the form of computed tomography (CT) or magnetic resonance imaging (MRI) immediately after surgery and at three to six months follow-up. All patients underwent regular postoperative visits at 14 days, six weeks, and three months. Patients with preoperative hydrocephalus, cerebellar hematoma or infarction requiring emergent surgery, or didn’t have all technical components performed were excluded.

\section{Surgical technique}

The technique of suboccipital craniotomy or craniectomy has been previously described. A brief summary follows. Informed consent was obtained prior to all operations. After the induction of general anesthesia and appropriate intravenous access and neuromonitoring is obtained, the patient is then positioned prone in the Mayfield head holder in a flexed position to enhance exposure to the posterior fossa. A midline incision is planned from the inion or above to the level of the spinous process of C2. The incision is then carried deeper with Bovie ${ }^{\circledR}$ electrocautery (Bovie Med Corp, Clearwater, FL) in the midline to the level of the fascia and suboccipital muscles. The occipital bone at the superior nuchal line is invested with a tough fibrous band consisting of the attachments of the trapezius muscles bilaterally and deeper, the semispinalis capitis muscles. In the standard approach, all muscles are detached in the midline in a subperiosteal fashion from the inion down for deeper exposure of the bony elements. At this stage, rather than a wide detachment of the musculature, a "T" shaped incision is made of the fascia to leave a transverse fascial cuff at the superior nuchal line as is illustrated in Figure 1 . 


\section{Cureus}

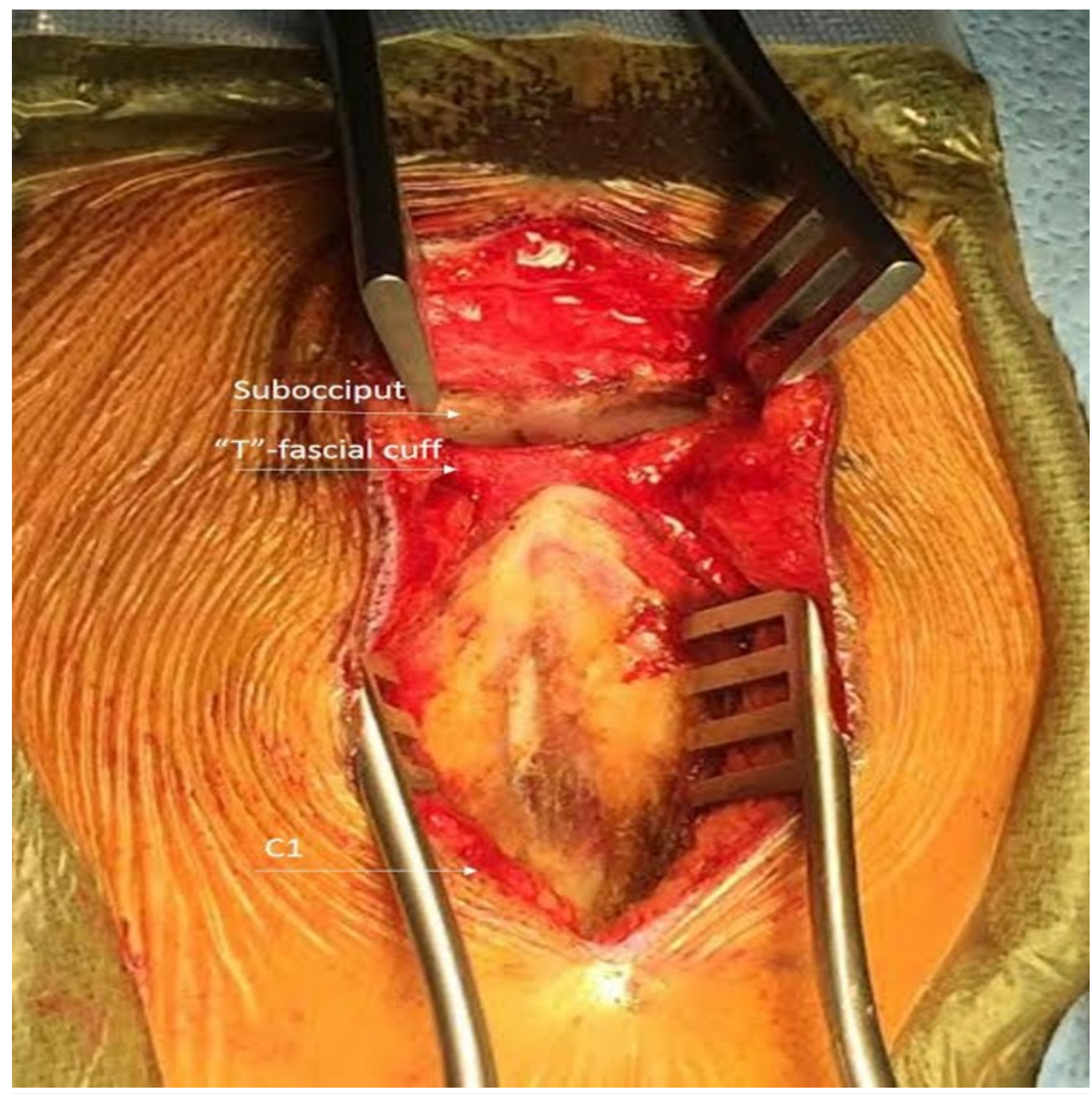

FIGURE 1: Intraoperative Photograph Highlighting the "T"fascial Cuff During the Initial Exposure for a Suboccipital Craniectomy

The fascia on each side of the midline is then reflected laterally with the underlying musculature. After completion of the intended intradural portion of the operation, the dura is closed in a watertight fashion, when possible. A dural sealant is applied to the suture line. The muscles are reapproximated to reduce dead space with O Vicryl ${ }^{\circledR}$ sutures (Ethicon, New Jersey, USA). The fascia on each of the midline is then closed medially and superiorly along the transverse fascial cuff in watertight fashion with interrupted O Vicryl sutures as shown in Figure 2 . 


\section{Cureus}

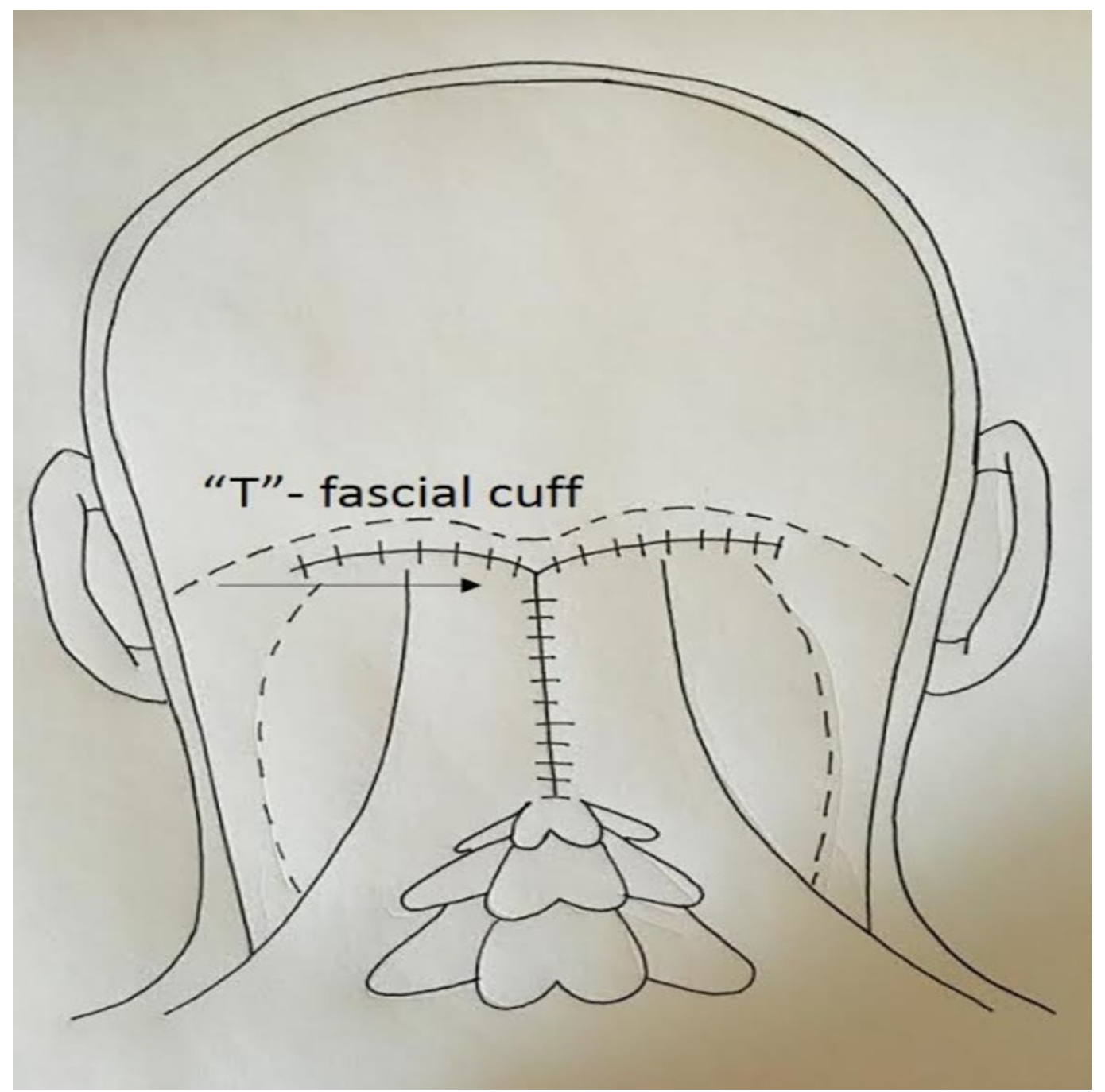

FIGURE 2: Artist's Impression of the "T"-fascial Cuff During the Operative Approach for a Suboccipital Operation

The rest of the wound is then closed in layers in the usual manner followed by a non-absorbable suture used to close the cutaneous layer in a running fashion. A drain is not placed.

\section{Case illustration}

A 34-year-old non-obese female with occipital headaches diagnosed with a Chiari malformation underwent an uneventful suboccipital craniectomy with duraplasty. Due to worsening headaches, a postoperative MRI shown in Figure 3 confirmed a clinically relevant pseudomeningocele. A lumbar tap was performed to rule out meningitis. 


\section{Cureus}

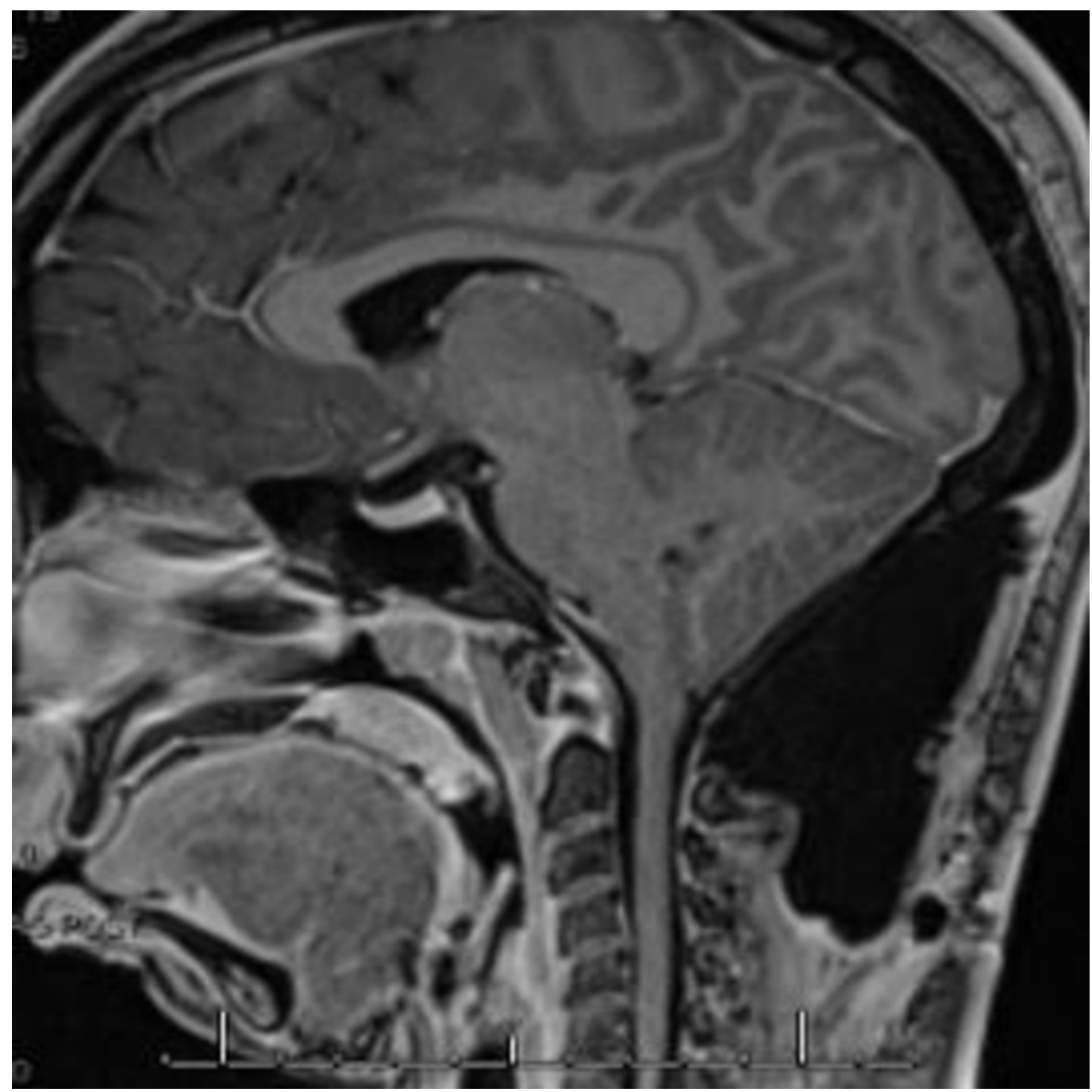

FIGURE 3: Postoperative Sagittal MRI After a Suboccipital Craniectomy in a Patient with a Delayed Diagnosis of Idiopathic Intracranial Hypertension

The opening pressure was noted to be above $50 \mathrm{~cm} \mathrm{H20} \mathrm{with} \mathrm{remarkable} \mathrm{relief} \mathrm{of} \mathrm{symptoms}$ after the procedure. An ophthalmological evaluation confirmed papilledema. The patient was diagnosed with idiopathic intracranial hypertension ( $\mathrm{IIH}$ ) and was treated with a lumboperitoneal shunt. Her symptoms immediately improved and her pseudomeningocele resolved at six months. This case highlights the reliability of the " $\mathrm{T}$ "-fascial closure, which the authors believe helped prevent a CSF fistula despite intracranial hypertension.

\section{Results}

Our retrospective review identified 33 patients matching the inclusion criteria. The mean age was 43 years old (range: $21-78$ ). Twenty-one patients underwent surgery for a Chiari 1 malformation and 12 for primary or metastatic tumor. An autologous pericranium graft $(n=5)$ or bovine pericardial graft $(n=28)$ was performed in cases to achieve a watertight closure. In patients without a watertight closure, an onlay collagen-based graft was placed on top of the remaining dura. A dural sealant was used in all cases. The bone flap was repositioned anatomically in eight cases. All patients had a minimum of at least six months follow-up. 
Overall, our cohort had a $21 \%$ (7/33) rate of clinical and radiographic pseudomeningocele formation with $9 \%(3 / 33)$ requiring surgical revision or a separate procedure. Of those utilizing the myofascial cuff preservation technique, there was a $12 \%(2 / 17)$ rate of a clinical and radiographic pseudomeningocele formation compared to $31 \%(5 / 16)$ in the standard cohort. The rate of permanent CSF diversion or revision was also less in the myofascial cuff preservation group at $6 \%(1 / 17)$ compared to $13 \%(2 / 16)$ in the standard. In all patients with persistent pseudomeningocele formation, there was no wound compromise nor evidence of CSF drainage.

\section{Discussion}

Pseudomeningocele formation and CSF leak represent a significant complication after posterior fossa surgery. Cerebrospinal fluid leak rates in the published literature range between 1.5\% 23\% [8-9]. A study by Dubey and colleagues revealed CSF leak, meningitis, and wound infection rates of $13 \%, 9.2 \%$, and $7 \%$, respectively, out of 500 patients. Reported pseudomeningocele rates from posterior fossa interventions range from $4 \%$ to $28 \%$ [10]. Litvack, et al. reported a $19.2 \%$ rate of pseudomeningocele formation after suboccipital decompression with duraplasty for Chiari I malformations. CSF-related complications can require readmissions and additional interventions with escalating costs.

A variety of technical modifications has been proposed to reduce the rate of pseudomeningocele formation and CSF leak after posterior fossa surgery. Performing a craniotomy versus craniectomy reduces pseudomeningocele formation [11-12]. The use of autologous dural grafts as compared to non-autologous dural grafts can lower rates of wound complications [13]. Furthermore, a reduced rate of CSF-related complications can be seen with a variety of commercially available dural sealants [14-16].

The technique described herein focuses on eliminating potential dead space and adding another water-tight layer to posterior fossa wound closures [17-18]. To our knowledge, this is the first closure technique of its kind to be analyzed as a method to decrease postoperative pseudomeningocele formation, although it has been postulated previously. These concepts have been applied to various surgical interventions, such as transsphenoidal surgery or skull base surgery, and highlight the importance of decreasing the potential space incited by the approach with an appropriate reconstruction of the operative defect [19].

The surgical technique is simple, fast, and only requires one additional step during exposure. Adding a second water-tight layer of closure is particularly helpful in patients with prior surgery or radiation where dural closure is not possible. In particular, the most superior aspect tends to be the most difficult position to close, due to the lack of attachment along the superior nuchal line. This is easily remedied by performing a T-shaped cuff at the initial dissection and allows for a firm attachment upon closure. The increased strength of this technique was demonstrated in the patient wherein a clinically relevant pseudomeningocele had formed but there was no drainage despite increased opening CSF pressures from the patient's idiopathic intracranial hypertension. This may be due to the fascial closure's ability to allow for the more superficial layers to heal due to the impeded flow of CSF.

There are several inherent weaknesses of this analysis. First, because of the non-blinded retrospective nature of the study, there may be bias in reviewing the clinical and radiographic evidence of pseudomeningocele formation. Second, there is a multitude of factors that contribute to CSF-related complications after posterior fossa surgery. Our limited series cannot control for all these factors. The type of dural graft or dural sealant used was not standardized in all cases. A prospective randomized controlled study is needed to clearly demonstrate a reduced rate of CSF-related complications. 


\section{Conclusions}

Preservation of the myofascial cuff for watertight fascial closure during posterior fossa surgery reduces the rate of pseudomeningocele formation and cerebrospinal fluid leak as compared with standard techniques. This restorative anatomical technique is simple, easily adoptable without added morbidity, and worth incorporating. A larger prospective multi-institutional study is necessary to corroborate these findings.

\section{Additional Information \\ Disclosures}

Human subjects: Consent was obtained by all participants in this study. Animal subjects: All authors have confirmed that this study did not involve animal subjects or tissue. Conflicts of interest: In compliance with the ICMJE uniform disclosure form, all authors declare the following: Payment/services info: All authors have declared that no financial support was received from any organization for the submitted work. Financial relationships: All authors have declared that they have no financial relationships at present or within the previous three years with any organizations that might have an interest in the submitted work. Other relationships: All authors have declared that there are no other relationships or activities that could appear to have influenced the submitted work.

\section{References}

1. Kubota M, Yamauchi T, Saeki N: Surgical Results of Foramen Magnum Decompression for Chiari Type 1 Malformation associated with Syringomyelia: A retrospective study on neuroradiological characters influencing shrinkage of syringes. Spinal Surg. 2004, 18:81-86. 10.2531/spinalsurg. 18.81

2. Agarwalla PK, Stapleton CJ, Ogilvy CS: Craniectomy in acute ischemic stroke . Neurosurgery. 2014, 74:S151-S162. 10.1227/NEU.0000000000000226

3. Moskowitz SI, Liu J, Krishnaney AA: Postoperative complications associated with dural substitutes in suboccipital craniotomies. Neurosurgery. 2009, 64:ons28-ons34. 10.1227/01.NEU.0000334414.79963.59

4. Yoshimoto T, Sawamura Y, Houkin K, Abe H: Effectiveness of fibrin glue for preventing postoperative extradural fluid leakage. Neurol Med Chir. 1997, 37:886-90. 10.2176/nmc.37.886

5. Cosgrove GR, Delashaw JB, Grotenhuis JA, Tew JM, Van Loveren H, Spetzler RF, Payner T, Rosseau G, Shaffrey ME, Hopkins LN, Byrne R, Norbash A: Safety and efficacy of a novel polyethylene glycol hydrogel sealant for watertight dural repair. J Neurosurg. 2007, 106:5258. 10.3171/jns.2007.106.1.52

6. Litvack ZN, Lindsay RA, Selden NR: Dura splitting decompression for Chiari I malformation in pediatric patients: clinical outcomes, healthcare costs, and resource utilization.. Neurosurgery. 2013, 72:922-29. 10.1227/NEU.0b013e31828ca1ed

7. Dubey A, Sung WS, Shaya M, Patwardhan R, Willis B, Smith D, Nanda A: Complications of posterior cranial fossa surgery--an institutional experience of 500 patients. Surg Neurol. 2009, 72:369-75. 10.1016/j.surneu.2009.04.001

8. Tu A, Tamburrini G, Steinbok P: Management of postoperative pseudomeningoceles: an international survey study. Childs Nerv Syst. 2014, 30:1791-801. 10.1007/s00381-014-2501-9

9. Youssef JA, McAfee PC, Patty CA, Raley E, DeBauche S, Shucosky E, Chotikul L: Minimally invasive surgery: lateral approach interbody fusion: results and review. Spine (Phila Pa 1976). 2010, 35:S302-11. 10.1097/BRS.0b013e3182023438

10. Mazzola CA, Fried AH: Revision surgery for Chiari malformation decompression. Neurosurg Focus. 2003, 15:E3. 10.3171/foc.2003.15.3.3

11. Gnanalingham KK, Lafuente J, Thompson D, Harkness W, Hayward R: Surgical procedures for posterior fossa tumors in children: does craniotomy lead to fewer complications than craniectomy?. J Neurosurg. 2002, 97:821-26. 10.3171/jns.2002.97.4.0821

12. Kurpad SN, Cohen AR: Posterior fossa craniotomy: an alternative to craniectomy . Pediatr Neurosurg. 1999, 31:54-57. 10.1159/000028833 


\section{Cureus}

13. Abla AA, Link T, Fusco D, Wilson DA, Sonntag VK: Comparison of dural grafts in Chiari decompression surgery: Review of the literature. J Craniovertebr Junction Spine. 2010, 1:2937. 10.4103/0974-8237.65479

14. Durham SR, Fjeld-Olenec K: Comparison of posterior fossa decompression with and without duraplasty for the surgical treatment of Chiari malformation Type I in pediatric patients: a meta-analysis. J Neurosurg Pediatr. 2008, 2:42-49. 10.3171/PED/2008/2/7/042

15. Kawai H, Nakagawa I, Nishimura F, Motoyama Y, Park YS, Nakamura M, Nakase H, Suzuki S, Ikada Y: Effectiveness of a new gelatin sealant system for dural closure . Neurol Res. 2014, 36:866-72. 10.1179/1743132814Y.0000000342

16. Than KD, Baird CJ, Olivi A: Polyethylene glycol hydrogel dural sealant may reduce incisional cerebrospinal fluid leak after posterior fossa surgery. Neurosurgery. 2008, 63:ons182-86. 10.1227/01.NEU.0000313116.28200.67

17. Perrini P: Technical nuances of autologous pericranium harvesting for dural closure in Chiari malformation surgery. J Neurol Surg B Skull Base. 2015, 76:90-93. 10.1055/s-0034-1389370

18. Lau T, Reintjes S, Olivera R, van Loveren HR, Agazzi S: C-shaped incision for lateral suboccipital approach: Anatomical study and clinical correlation. J Neurol Surg B Skull Base. 2015, 76:117-21. 10.1055/s-0034-1390396

19. Djordjevic Z, Milosavlijevic B: Postoperative cerebrospinal fluid fistulas and their treatment . J Neurosurg Sci. 1974, 18:109-11. 